\title{
O MARCA-PASSO DAS EMOÇÕES NO RITMO DE CRIANÇAS PORTUGUESAS COM NECESSIDADES EDUCATIVAS ESPECIAIS (ESTUDO DE CASO)
}

\author{
THE PACEMAKERS OF EMOTIONS IN THE RHYTHM OF PORTUGUESE CHILDREN \\ WITH SPECIAL EDUCATIONAL NEEDS (CASE STUDY)
}

Ernesto Candeias Martins ${ }^{1}$

\begin{abstract}
Resumo
Estudo de caso (metodologia qualitativa) realizado em 2013sobre inteligência emocional em alunos portugueses, frequentando $1 .^{\circ}$ ciclo educação básica, com idades de 6-7 anos de 2 escolas urbanas: 2 crianças $(\mathrm{M}=$ microcefalia, $\mathrm{A}=$ autismo atípico); 2 crianças $(\mathrm{N}=$ criança normal, $\mathrm{H}=$ perturbação de hiperatividade com défice de atenção). Os objetivos pretenderam:Demonstrar a importância das emoções na aprendizagem; identificar e lidar com as emoções em situações; propor estratégias para cada criança, aquando dos resultados obtidos com aplicação do teste projetivo e utilizaçãomaterial didático. Metodologia: atividades com "Uma caixa cheia de emoções'; prova projetiva "Era uma vez..." Teresa Fagulha; ficha de anamnese aos pais; análise documental aos processos; observação participante; notas de campo e triangulação. Os resultados permitiram estabelecer estratégias para diminuir os fatores de distratibilidade, facilitar a atenção com material visualmente atrativo e manuseável e fornecer instruções acompanhadas de observação. Houve dificuldades nos sujeitos em identificar a 'ira' e 'raiva'.
\end{abstract}

Palavras-chave: emoções. inteligência emocional. perturbação de hiperactividade com défice de atenção. necessidades educativas especiais. educação básica.

\begin{abstract}
Case study in 2013 of qualitative methodology, about emotional intelligence in Portuguese students with NEE (application program for emotions education), ages 6-7 years of 2 urban schools attending 1 st basic education cycle: 2 children $(\mathrm{M}=$ microcephaly, $\mathrm{A}=$ atypical autism); 2 children $(\mathrm{N}=$ ' normal ' child, $\mathrm{H}=$ disorder hyperactivity with attention deficit. Intended objectives: demonstrate the importance of emotions in learning; identify and deal with various emotions in emotional situations; propose strategies for each child, vis-à-vis its pathology, in the results obtained by application of projective test and use didactic material. Methodology: activities with the pack "A box full of emotions '; application of projective test "once upon a time ..." Teresa Spark; anamnesis sheet to parents; documentary analysis

1 É Doutor e Mestre em Ciências da Educação, licenciado em Filosofia (Univ. Católica Portuguesa) e em Pedagogia/Ciências da Educação (Univ. de Salamanca/Univ. de Lisboa). Docente no Instituto Politécnico de Castelo Branco/Escola Superior de Educação (1988--), onde tem ocupado vários cargos diretivos e de coordenação de cursos. Membro fundador da SPCE (Sociedade Portuguesa de Ciências da Educação), Presidente da Associação HiscultEDUCA, membro Sociedad Española de Pedagogia, do Institut Estuds Catalans e da Associação Histeduc, etc. Consultor de Agrupamentos de Escola e investigador do CeiED - Universidade Lusófona de Lisboa. E-mail: ernesto@ipcb.pt
\end{abstract}


procedures; participant observation; field notes and data triangulation. The results establish strategies to decrease the factors of distractibility to facilitate attention with visually attractive and manageable material and provide instructions accompanied by observation. There were difficulties in the subject to identify the 'wrath ' and ' anger '.

Keywords: emotional intelligence emotions. with hyperactivity disorder attention deficit.special educational needs. basic education.

\section{Questões introdutórias}

As emoções são uma parte importante na vida humana que têm suscitado interesse científico, já que as experimentamos sem que por vezes as refletimos. O cérebro é o comando fundamental das emoções, que explica a sua base fisiológica, mas também é afetado, ao longo do desenvolvimento, pelas diferentes experiências e acontecimentos de vida. (BISQUERRA, 2012; CARPENA, 2003; MORENO; PALENCIA, 2001).

Muitos alunos na sua escolaridade apresentam dificuldades de aprendizagem e de relacionamento entre os seus pares. A falta de habilidades sociais e duma alfabetização emocional, o desenvolvimento da capacidade de identificar e conhecer as emoções próprias e dos outros, é primordial na educação, tendo efeitosna aprendizagem (BISQUERRA; LÓPEZ, 2007; GROP, 2009). As causas dessas dificuldades de aprendizagem têm sido as cognitivas,já que a intervenção realizada por meio do treino cognitivo nem sempre deu atenção à questão emocional (SHORE,1994). De facto, ter um elevado quociente de inteligência não é garantia de êxito, uma vez que a inteligência envolve, não apenas a capacidade cognitiva mas, também, a perceção, a expressão e o controlo das emoções.É fundamental que o aluno adquira competências científicas e técnicas, mas tambémaprenda a lidar com as emoções, para ter sucesso nas suas relações intra e interpessoais.

A nossa investigação é um estudo de caso (exploratório, descritivo, interpretativo), do paradigma qualitativo, que aborda a educação para as emoções, a inteligência emocional e habilidades sociais, procurando compreender como 2 crianças com necessidades educativas especiais (NEE) (microcefalia, autismo atípico) e outras duas,que não possuem qualquer referenciação (uma normal e outracom perturbação de hiperatividade com défice de atenção PHDA) não incluída no Dec. Lei no 3/2008, de 7 de janeiro (em vigor), identificam, gerem e controlam as emoções e como desenvolve as habilidades emocionais. Sabemos que as crianças com NEE têm mais dificuldade naidentificação das emoções que as outras, por isso querermos compreender a intervenção nesta área. Os alunos do estudofrequentavam o $1 .^{\circ}$ ciclo da educação básica em 2escolas portuguesasdo interior (Nisa, Guarda). 
O estudo decorreu no 1..$^{\circ}$ trimestre de 2013, inserido num Projeto de Inteligência Emocional, norteando-se pelas seguintes questões de investigação:demonstrar a importância da educação para as emoções em contexto escolar; compreender a dimensão emocional nas crianças com NEE; descrever como as criançasem estudo reconhecem e lidam com as diversas situaçõesemocionais que lhe são apresentadas;propor estratégias para este tipo crianças, face à patologia apresentada e aosresultados obtidos pela aplicação dum teste projetivo (FAGULHA, 2003, 2010) e do material didático "Uma caixa cheia de emoções" (KOG; MOONS; DEPONDT, 2004), com atividades.

\section{A TEORIA FUNDAMENTADA DO ESTUDO}

O termo emoção (latim: 'emovere') significa'fazer movimento a partir de', 'estar excitado', sair doseu presente estado por meio de qualquer coisa que agita, move ou abala (BISQUERRA, 2009). Perante esta referência semântica reconhecemos que a emoção é algo que parte do interior do sujeito e que seexteriorizana relação com o meio envolvente (BISQUERRA; PÉREZ, 2007, p. 68-72). Ou seja, é uma reação complexa desencadeada por um estímulo ou pensamento, que envolve reacções orgânicas e sensações pessoais. Sendo uma resposta envolve vários componentes, reações, excitação fisiológica, interpretação cognitiva e experiência subjetiva.H. Wallon (1968) consideravaas emoções como manifestações de estados subjetivos com componentesorgânicos (contrações musculares, viscerais, etc.). Para ele a emoção era o primeiro e o mais forte vínculo estabelecido entre o sujeito e as pessoas do ambiente, constituindo as manifestações iniciais dos estados subjetivos, apresentando três propriedades: contagiosidade - a capacidade de contaminar o outro; plasticidade - a capacidade de refletir sobre ocorpo, os seus sinais; regressividade - a capacidade de regredir as atividades ao raciocínio. Caberia às manifestações emocionais, através do seu poder de contágio, sensibilizar as pessoas do ambiente para satisfazer necessidades e desejos (WALLON, 1978). Por seu lado, Goleman (1996) interpreta a emoção referindo-se a um sentimento e raciocínios daí derivados, aos estados psicológicos e biológicos e ao leque de propensões para a ação.

Sabe-se que há centenas de emoções, umas simples e outras complexas, com combinações, variações, mutações e tonalidades. A. Damásio (2000), numa simplificação do processo neurobiológico, considera a emoção como uma variação psicofísica, desencadeada por um estímulo, subjectivamente experimentado e que coloca num estado de resposta ao 
estímulo, isto é, as emoções são um meio natural de avaliar o ambiente que nos rodeia e de reagir de forma adaptativa. Deste modo a emoção remete-nos para 6 emoções primárias e/ou universais (DAMÁSIO, 1994). Existem outroscomportamentos a que têm sido atribuídos o rótulo de 'emoção', designadas poremoções secundárias ou sociais (vergonha, culpa), as quais Damásio (2000) denomina 'emoções de fundo'. Reconhecemos queas emoções são preponderante no desenvolvimento, já que é por meio delas exteriorizamos desejos evontades (ARÀNDIGA, 2006; SALMURRI, 2004). Ou seja, são manifestações que expressam um universo percetível, mas pouco estimulado nos modelos de ensino e unidades curriculares.

\subsection{A relação da emoção e o sentimento}

A. Damásio (2000, 2012)distingue entre a tipologia de emoções, as seguintes:

*-Emoções primárias e universais. Surgem na infância, sendo úteis para uma reação rápida quando emergem determinados estímulos do meio, envolvendo um elevado fluxo de energia, de tal maneira que podem existir sem termos consciência delas, caso sejam inatas. Refletem diretamente as mudanças dos estados de espírito, pois inscrevem-se nas estruturas neurobiológicas do ser humano, sendo responsáveis pela sobrevivência, enquanto individuo biológico (alegria, tristeza, medo, cólera, surpresa, raiva, aversão).

*-Emoções secundárias e sociais. São as relacionadas com a vida do homem, enquanto ser social, já que implicam uma avaliação cognitiva das situações, envolvendo, por isso, as áreas do córtex pré-frontal. São experimentadas mais tarde, dependem de uma aprendizagem e, portanto, de interações sociais (vergonha, culpa, orgulho, ciúme).

*-Emoções de fundo. Sãocausadas por um esforço físico intenso, pelo remoer de uma decisão complicada de tomar ou pela ansiedade em relação a um acontecimento agradável ou desagradável que nos espera (bem-estar, mal-estar, calma, tensão).

Por outro lado, o sentimento, segundoDamásio (1999), acontece após a emoção, já que o uso habitual da 'emoção' tende a incluir a noção de sentimento. Na tentativa de compreender a cadeia complexa de acontecimentos que começa numa emoção e termina no sentimento, o separar a parte do processo que se torna pública, da parte do processo que sempre se mantém privada,ajudaa clarificar-nos. Aquele neurocientista atribui à parte públicaa 'emoção' e à parte privada ‘sentimento' (DAMÁSIO, 2012, p. 32-48), uma vez que os sentimentos são a expressão do florescimento ou sofrimento humano na mente e corpo. É óbvio que os sentimentos não são uma mera decoração das emoções ou qualquer coisa que 
guardamos ou deitamos fora. São imagens de revelações da vida dentro de nós(mente) que no quotidiano expressam a nossa grandeza e pequeneza. Quando tomamos consciência das nossas emoções surge o sentimento, que se dá quando as nossas emoçõesse transferem para zonas do cérebro, onde são codificadas pela atividade neuronal: "As emoções ocorrem no teatro do corpo. Os sentimentos ocorrem no teatro da mente". (DAMÁSIO,1994, p. 35).

Há, pois uma confusão terminológica entre emoção esentimento, visto que são dois processos relacionados entre si, mas diferentes.A sua análise semânticaretrata dois conjuntos distintos: 'sentimento' usa-se na experiência mental duma emoção; e o uso da 'emoção'no conjunto de reações aos estímulos externos, muitas delas observáveis. A. Damásio (2000, p. 55-71) aborda-os na base neural, distinguindo três etapas de processamento contínuo:o estado de emoção pode ser desencadeado e executado inconscientemente; o estado de sentimento pode ser representado inconscientemente;o estado de sentimento tornado consciente, que é conhecido pelo organismo, tem emoção e sentimento. A diferença está que o sentimento (experiência mentalda emoção) e a emoção (conjunto de reações orgânicas) estabelecem fundamentos biológicos que ligam o estado de sentimento à consciência. Na prática significa que não podemos observar um sentimento noutra pessoa, apesar de podermos observar alguns aspetos emocionais que originam essessentimentos.

Na verdade, asemoções ocorrem no contexto de consciência, possibilitando observar um sentimento em nós próprios, sentindo as nossas emoções e sabermos que as sentimos. A trama da nossa mente e do nosso comportamento é tecida à volta de ciclos sucessivos de emoções seguidas por sentimentos, que se tornam conhecidos e geram novas emoções, numa polifoniacontínua que sublinha e pontua pensamentos específicos na nossa mente e ações do nosso comportamento. (CARPENA, 2003).

Já deixámos antever queWallon (1968) atribui às emoções um papel importante na formação da vida psíquica, pois funcionacomo uma amálgama entre o social e o orgânico. Por exemplo, as relações da criança com o mundo exterior são relações de sociabilidade, visto que, ao nascer, não tem meios de ação sobreas coisas circundantes, razão pela qual procura a satisfação das suas necessidades e desejos de concretização por meiodos adultos. Por isso, os primeiros sistemas de reação, organizados sob a influência do ambiente, as emoções tendem a realizar (manifestações consoantes e contagiosas), uma fusão de sensibilidade entre o indivíduo e o seu 'entourage'. Nesseperíodo de desenvolvimento há a proximidade do 'outro', ondeas emoções sãoo primeiro e mais forte vínculo entre os indivíduos eo ambiente social. 
Essas manifestações iniciais assumem um caráter de comunicação, sendo vistas como o meio de sobrevivência típico da espécie humana.

Os únicos atos úteis que a criança pode fazer, consistem no fato de, pelos seus gritos, pelas suasatitudes, pelas suas gesticulações, chamar a mãe em seu auxílio [...] Portanto, os primeiros gestos [...] não são gestos que lhe permitirão apropriar-se dos objetos do mundo exterior ou evitá-los, são gestosdirigidos às pessoas, de expressão. (WALLON, 1978, p. 201).

Esta distinção entre emoção e afetividade permite a Wallon (1968) considerar as emoções como manifestações dos estados subjetivos, com componentes orgânicas. Ao defender o caráter biológico das emoções, insiste que estas são originadas na função tónica e, por issoidentifica: emoções de natureza hipotónica, redutoras do tónus, tais como o susto e a depressão; emoções hipertónicas, geradoras de tónus, como a cólera e a ansiedade, capazes de tornar pétrea a musculatura periférica.Por sua vez a afetividade tem uma conceção mais ampla, envolvendo um leque de manifestações que engloba os sentimentos (origem psicológica) e emoções (origem biológica), correspondendo a um período mais tardio na evolução da criança, quando surgem os elementos simbólicos. É este aparecimento que provoca a transformação das emoções em sentimentos. O próprio processo deaprendizagem ocorre em consequência dessasinterações sucessivas.

Relativamente às perspectivas sobre as emoções há diversas interpretações:

*-Perspetiva evolutiva desenvolvida por Darwin que identificou, pelas expressõeshumanas, seis emoções primárias (alegria, tristeza, cólera, desgosto, surpresa, medo).

*-Perspetiva fisiológica, que impulsou a teoria das emoções deWilliam James e C. Lange, que se pautava pela relação da experiência subjetiva com os processos fisiológicos, em que as emoções seriam o resultado dos estados fisiológicos desencadeados por estímulos ou situações ambientais(NEWEN e ZINK, 2009). Aquela teoria foi criticada por W. Cannone Philip Bard (BISQUERRA, 2009), que pensam que as emoções têm origem no cérebro, ocorrem ao mesmo tempo que as reações fisiológicas, mas não sãocausadas por estas. Ou seja, os estímulos emocionais têm dois efeitos excitatórios independentes que provocam o sentimento da emoção no cérebro, bem como a sua expressão no sistema nervoso autónomo e somático (estímulos).

*-Perspetiva cognitivista. A cognição constitui um ingrediente essencial da emoção. Neste sentido Stanley Schachter propôs a teoria dos dois fatores, em que as emoções possuem dois ingredientes: excitação física e um rótulo cognitivo. Assim a experiência emocional cresce a partir da nossa consciência de excitação do corpo (SLUYTER; SALOVEY, 1999). Schachter 
considerava que as emoções são fisiologicamente similares, já que umaexperiência emocional exige interpretação consciente da excitação. Assim, asnossas cognições constituem um elemento fundamental no desencadeamento das emoções e no encarar uma situação causadora de emoções.

*-Perspetiva cultural, que consideraas emoções como comportamentos apreendidos na socialização. Cada cultura tem diferentes formas de exprimir as diferentes emoções, por isso seriam uma construção social que exige uma aprendizagem dependente da cultura. O tipo de emoções que se manifesta em cada situação, a forma como são demonstradas e o conjunto de regras específicasde cada cultura implica uma linguagem para a emoção específica, que deve ser reconhecida por todos aqueles que nela estão inseridos.

\subsection{Inteligência emocional e educação das emoções}

A psicologia tem estudado a inteligência humana mais no âmbito dascapacidades cognitivas, que na parte emocional ou capacidade para reconhecer, expressar e gerir emoções (PICARD; COSIER, 1997, p. 151). Hojeatribuímosum papel de relevo às emoções nos processos cognitivos e no bem-estar psicológico do sujeito. Não existe um único tipo de inteligência para se ter êxito, mas uma gama de sete inteligências (GOLEMAN, 1996): linguística, musical, lógico-matemática, espacial, corporal cinestésica e as inteligências pessoais. Estas inteligências, segundo Gardner (2000), podem ser: intrapessoale interpessoal. A primeira permite entender e responder adequadamente a humores, temperamentos, motivações e desejos de outras pessoas, daí o sujeito relacionar-se com os outros e compreendê-los, uma vez que influencia o desenvolvimento social. Salovey y Mayer (1990) incluem nesta inteligência as capacidades de liderança, de estabelecer relações e manter amizades, de resolver conflitos e possuir capacidade de análise social. A inteligência intrapessoal permite ao sujeito compreender-se a si mesmo, conhecer-se melhor e atuar conforme esse conhecimento (VALLÉS; VALLÉS, 2000; SMITH; STRICK, 2001). Trata-se do correspondente interno da inteligência interpessoal, isto é, da habilidade de acesso aos sentimentos, sonhos e ideias, discriminando-os e utilizando-os na solução de problemas e no reconhecimento de desejos, necessidades e capacidades para formular uma imagem precisa de si próprio e para usar essa imagem. Este é o tipo de inteligência que qualquer pessoa autorreflexiva possui.Éfundamental que o indivíduo adquira confiança em si próprio, possua 
autonomia e facilidade relacional,bem como aptidões para comunicar e capacidade para dominar as suas emoções, para além dascapacidades e competências técnicas.

Existem, no mínimo, três elementos que determinam a inteligência emocional: capacidade de perceber, avaliar e expressar corretamente uma emoção; capacidade deoriginar ou ter acesso a sentimentos quando eles permitirem auxiliar na compreensão de si mesmo ou deoutrem; capacidade de compreender as 6 emoções e o conhecimento decorrente dela; capacidade decontrolar as próprias emoções para fomentar o crescimento emocional e intelectual. (SALOVEY; MAYER, 1990; SHORE, 1994).

Por conseguinte, a componente afetiva é crucial no desenvolvimento normal da criança e na sua educação (ASENSIO, 2006, p. 62-69), já que o seu déficenaarticulação do desenvolvimento cognitivo e emocionaltem consequências inquietantes nas aptidões cognitivas das novas. É, pois importante que a criança desenvolva a sua inteligência emocional ou a capacidade de perceber emoções, sabendo controlá-las, de modo a ajudar o pensamento a compreendê-las e a promovero seu crescimento emocional e cognitivo (SLUYTER; SALOVEY, 1999, p. 72-88). Ao nível escolar os alunos necessitam de lidar com as emoções, aprender a reagir às frustrações,ansiedade,zanga, angústias, medos, tristezas, raiva/ira, etc. promovendo o autoconhecimento emocional e o diálogo com os outros.Compete à escola e à família educar para as emoções para desenvolver a inteligência emocional. (ARÀNDIGA, 2006).

Sabemos que toda a aprendizagem que seja feita com elevado conteúdo emocional é mais eficaz que outra desprovida de emoção.Se a emoção é parte integrante da cognição, o professor deve estar consciente de que ela está presente e estabelece um interfacecom os atos cognitivos de aprender (CARPENA, 2003). O clima emocional que se desenvolve na sala de aula interfere diretamente nas atitudes e práticas de aprendizagem. Por isso, na relação pedagógica é essencial que as emoções positivas prevaleçam sobre as negativas, para que professores e alunos mantenham o entusiasmo e interesse pelo ensino-aprendizagem. $\mathrm{O}$ professor deve consciencializar-se do trabalho emocional nos alunos, gerindo os desafios de ensinar turmas e alunos (incluindo os NEE) com diferentes motivações, histórias pessoais e capacidades de aprendizagem diferentes em contextos diversos. O compromisso e o relacionamento emocional entre professor e alunosão importantes para elevar os 'standards', como o conteúdo intelectual da própria aula e melhoria doscomportamentos eda motivação. 


\subsection{Autismo, microcefalia e PHDA}

Os sujeitos do nosso estudo apresentam algumas perturbações. As Perturbações do Espectro Autista (PEA) estão relacionadas com o desenvolvimento da criança, caracterizadas por um conjunto de sintomas e provocadas por um problema a nível neurológico que podem causar mudanças significativas a nível da socialização, da comunicação e comportamento (CUXART, 2000; RIVIÉRE, 2001). As caraterísticas gerais do PEA situam-se na comunicação e linguagem, no âmbito cognitivo (perceção, processamento da informação, atenção, memória, raciocínio), nas relações sociais, na conduta, autonomia, habilidades especiais (musicais, desenhar, memória literal e construtiva), etc. (SHORE, 1994). Um dos sintomas mais comuns são os problemas relacionados com a interação social, por exemplo problemas de socialização: evitar olhar para os olhos de outrem; preferir brincar sozinho; não partilhar interesses com os outros;interagir para obter um determinado objetivo desejado; ser inexpressivo ou expressões faciais não condizentes; não compreender os limites do seu espaço pessoal; resistir ao contato físico; não ser confortado em situações de aflição; não entender os sentimentos das outras pessoas ou de falar acerca dos seus; ter uma regulação prejudicada dos afetos (a raiva transforma-se em fúria, a ansiedade em pânico); possuir sensibilidade social prejudicada (são pessoas exclusivistas, só aceitam as coisas à sua maneira).

Amicrocefaliaé uma condição neurológica em que o tamanho da cabeça é menor do que o tamanho típico para a idade. Pode ser congénita, adquirida ou desenvolver-se nos primeiros anos de vida ou, então provocada pela exposição a substâncias nocivas durante o desenvolvimento fetal ouestar associada com problemas ou síndromes genéticos hereditários.Os portadores de microcefalia não apresentam dificuldades no reconhecimento nem na manifestaçãodas emoções, contudoo atraso mental da criança terá de ser estimulada.

A Perturbação de Hiperatividade com Défice de Atenção (PHDA) é uma condição física que se caracteriza (ANTUNES, 2012): subdesenvolvimento e mau funcionamento de certas partes do cérebro; má comunicação entre os neurónios; menor e menos eficaz atividade elétrica; menor circulação sanguínea no cérebro; má gestão/utilização da glucose que é o principal combustível do cérebro; baixa resistência à frustração, pelo que a recompensa tem de ser imediata; zangam-se com facilidade, exageram nas respostas emocionais e afastam quem osajuda; incidem na adoção de comportamentos desagradáveis (mentir, dizer palavrões, culpar os outros pelos seus erros, discutir frequentemente, realizar pequenos furtos, etc.). 


\section{METODOLOGIA EMPÍRICA}

É um estudo de caso, no âmbito da metodologia qualitativa que pretendeu analisar em pormenor casos individuais com certas patologias, pois o objetivo é o de explorar, descrever ou explicar reações e intervenções, que proporcionem conhecimentos acerca do fenómeno (YIN, 1994) específico (inteligência emocional). Aplicámosinstrumentos que permitiram analisar e interpretar as emoções em crianças escolarizadas, com patologias diversas (microcefalia, autismo atípico e PHDA), através da metodologia de investigação-ação, desenvolvendo um programa de intervenção (sessões de atividades) com recurso ao material didático do pack "Uma caixa cheia de" (DEPONDT; KOG; MOONS,2004) e à prova projetiva “Era uma vez..."(FAGULHA, 2010). Utilizámos diversas técnicas derecolha de dados eregisto de notas de campo. Cumprimos as regras éticas e legais, quer no 'Protocolo' (formalização, autorização, termo de livre consentimento) aos responsáveis dos dois Agrupamentos de Escolas, aos pais e professores da turma e educação especial, quer nas entrevistas informais, fichas de anamnese, consulta documental individual, assim como na análise das atividades (triangulação de dados). (GUERRA, 2008).

\subsection{Técnicas de recolha de dados}

No estudo utilizámos um leque de técnicas de modo a compreender e interpretar osdados provenientes da nossa intervenção(programa) e observação:

\subsubsection{Observação documental, naturalista e participante}

Analisámos a legislação em vigor, os processos individuais dos alunos, o projeto educativo, o rendimento escolar e outros documentos fornecidos pelas professoras de turma e de educação especial. Associámos essa análise de conteúdo (categorização, registo de evidências) às informações das entrevistas informais e observações (natural, espontânea e participante no contexto de sala de aula ena realização das atividades através do registo de notas de campo e triangulação dos dados da ficha anamnese e prova projetiva e material didático (caixa das emoções). 


\subsubsection{Ficha de anamnese}

Trata-se dum roteiro, preenchido pelos pais das crianças, que se compõe de seis blocos:os dados de identificação; situação sociofamiliar (caraterização do agregado familiar); etapas do desenvolvimento; história clínica; história dodesenvolvimento e estado atual;levantamento das necessidades e recursos. As fichas de anamnese do aluno com PHDA e da criança N -'normal' foram preenchidas mediante uma entrevista informal com os respetivos pais. No caso das outras crianças, as fichas já se encontravam nos processos individuais, mas optámos por novo preenchimento.

\subsection{3 "Uma caixa cheia de emoções"}

Este pack compõe-se por um conjunto de material didático que permite ajudar a (re) conhecer melhor as emoções dos alunos (DEPONDT; KOG; MOONS, 2004). A criança pode fazer esse reconhecimento tanto nela própria, como nos outros, desenvolvendo a sua consciência social, identificando emoções e os sentimentos, com base nos sinais corporais e aprendendo a dar-lhe um nome. Este material destina-se a crianças do jardim-de-infância, do $1^{\circ}$ Ciclo do Ensino Básico e acrianças com NEE. A caixa compõe-se por gravuras (4 emoções),16 fichas, por cartões-situação (total de 48 cartões, sendo 12 para cada emoção, com uma história ou indicações no verso), por máscaras, fantoches, músicas originais, etc. tudo com o intuito de explorar as quatro emoções básicas: 'estar feliz’;'estar com medo';‘estar zangado';'estar triste'.

\subsubsection{Prova projetiva "Era uma vez...", de Teresa Fagulha}

A prova projetiva "Era uma vez..." destina-se a crianças dos 5 aos 11 anos, com o objetivo de analisar a forma como elas analisam as emoções, nomeadamente a ansiedade e o prazer, os estados afetivos que têm uma função adaptativa e relevância particular no desenvolvimento psicológico (FAGULHA, 2003). Este teste é designado de temático, uma vez que a criança elaborar uma história a partir dos estímulos apresentados (FAGULHA, 2010). É constituído por um manual técnico; caderno de registo; folha de análise; cartões com figuras (femininas, masculinas). Compõe-se por cartões de desenhos que contam uma história não acabada, apresentada em formato de banda desenhada. Na prática apresentam-se as três sequências iniciais e a criança dácontinuação à história, escolhendo para esse efeito 3 cartões 
e a conclusão também já está pré-estabelecida ('cartão de fim'). Ou seja, a criança cria oito histórias, sendo a primeira de exemplo. A análise da prova é feita no quadro concetual das teorias psicodinâmicas, na base das teorias de Freud, Klein e Winnicott. (ESTRADA, 2008).

2.1.5 Notas de campo e triangulação de dados

Utilizámos ao longo do estudo as notas de campo que no dizer de Bogdan y Biklen (1994, p. 150) são "o relato escrito daquilo que o investigador ouve, vê, experiencia e pensa no decurso da recolha e refletindo sobre os dados de um estudo". Nesse registo adotámos dois procedimentos: um descritivo, em que a preocupação é a de registar palavras e ações entre situações observadas (evidências); e o reflexivo (interpretação). (BOGDAN; BIKLEN, 1994, p.167). Por isso, focámo-nos nos seguintes aspetos: caraterização; reconstruções de diálogos, observações e entrevistas informais; descrição das atividades, relatos de acontecimentos ou comportamentos; análise das reações emocionais das crianças; etc. Após a recolha dos dados aplicámos a triangulação de dados unida à triangulação de metodologias.

\section{A CARATERIZAÇÃO DOS SUJEITOS NO SEU CONTEXTO}

Neste ponto incidimos na análise e descrição das categorias de cada criança:

\subsection{Sujeito com Microcefalia - M}

*-Categoria 'Escola'. Este aluno frequenta a Escola Básica do $1^{\circ}$ Ciclo do Agrupamento de Escolas de Nisa (Distrito de Portalegre). A acessibilidade pedonal é muito satisfatória, tendo em conta que se encontra localizada na zona central da vila. Os meios de transporte encontram-se próximos da escola e correspondem às normas dos equipamentos educativos, bons espaços, com turmas com média de 23 alunos por sala e apoio às crianças NEE. $\mathrm{O}$ espaço exterior é amplo para o recreio,práticadesportiva e outras modalidades, com um parque e diversos espaços verdes.

*-Categoria 'Turma'. É uma turma mista (2. e $3 .^{\circ}$ anos), constituída por 20 alunos, 4 dos quais sãorepetentes e referenciados, com uma média de idades entre os 8/ 9 anos.

*-Categoria 'Dados clínicos'. O aluno apresenta uma microcefalia de causa não esclarecida, com dificuldade intelectual edesenvolvimental de grau moderado a grave e com prognóstico reservado. As suas maiores limitações sãomotoras, cognitivas e de comunicação, ou seja um 
atraso psicomotor, que se revela na rapidez docomportamento e no tempo de resposta o que envolve componentes motoras e psicológicos.Apresenta uma diminuição do tónus o que lhe proporciona uma diminuição da força musculare lhe condiciona a coordenação de movimentos e a sua funcionalidade. Da mesma forma, tambémcompromete o equilíbrio estático e dinâmico, apresentando-se com alterações e diminuição a nível dosreflexos automáticos de correção postural e de equilíbrio.

*-Categoria 'Percurso escolar'. Esta criançafrequentou uma crecheparticularaté ao ano letivo 2008/2009, depoiso Ensino Pré-escolar e ingressou no ensino básico com 6 anos.

*-Categoria História familiar.O processo individual do aluno e a recolha de informação junto dos pais (entrevistas), aquando dopreenchimento da ficha de anamnese, possibilitou-nos conhecer a sua família. É uma criança limpa e cuidada, vive com os pais e com um irmão ainda bebé. A mãe é funcionária dum hipermercado e o pai motorista. Os pais apresentam um nível económico médio etêm ambos o 9..$^{\circ}$ ano de escolaridade. Estão muito presentes na educação do filho, considerando que fazem tudo o que está ao seu alcance para lhe dar as condições mais adequadas. São muito recetivos a todas as sugestões da professora da turma e da professora de Educação Especial, da psicóloga e equipa de pedopsiquiatria que acompanha o aluno, que vai a todas as consultas marcadas, incluindo as de desenvolvimento em Coimbra. *Categoria 'Caracterização'.É um aluno com graves problemas cognitivos, de comunicação e fala, já que manifesta dificuldades graves na capacidade para comunicar e receber mensagensnão-verbais. Da observação efetuada e das entrevistasà professora de Educação Especial, nocontexto de sala de aula, a criança comunica com os adultos recorrendo à mímica facial, puxando a mãodo adulto ou deslocando-se para os locais ou objetos pretendidos.Não tem o controlo dos esfíncteres, nem come sozinha. Tem dificuldades nas atividades demotricidade fina da mão, isto é, não tem individualização da atividade motora dos dedos, não realizamovimentos de coordenação, o que implica uma fraca destreza manual uni e bilateral. Em relação às competências, ao nível dos movimentos largos e finos, elaadquiriu a marcha autónoma, embora por vezes caia, sendo necessário apoio e quando não existe gatinha.

O aluno manifesta, ao nível da aprendizagem e aplicação de conhecimentos, muitas dificuldades,havendo regressões em relação ao adquirido, sendo necessário reforçospermanentes. No entanto, já desenvolveu um conjunto de competências como apontar para si próprio, reconhecer os adultos pelo nome, juntar objetos às figuras dos mesmos, identificar figuras nomeadas, identificar personagens de uma história conhecida tendo, como 
suporte o livro, entre outras. Ao nível emocional tem manifestações de contentamento ou de tristeza ajustadas aosacontecimentos, às rotinas do dia que mais lhe agradam e às orientações que os adultos lhe dão. Apesarde não ter linguagem verbal, possui comportamentos comunicativos como: sorrir para outra pessoa; emitir sinais para chamar a atenção; esticar a mão ou olhar para algo que quer obter; usar gestos simples, por exemplo referir as partes do corpo nele e nos outros, apontando com a mão; exprimir emoções, normalmente movendo o corpo; exprimir recusa pela birra e/ou exprimir o sim através do sorriso; cumpre ordens e reage ao ritmo da música com movimentos do corpo. A criança tem muitas dificuldades em manter a atenção e concentração pelo período de tempo necessário, distraindo-se facilmente. Devido à sua problemática, encontra-se a fazer um ensino baseado no computador de monitor táctil, fazendo nele as suas aprendizagens (programas Grid e Boardmaker), as áreas e os temas a que se propõe. $\mathrm{O}$ aluno tem um currículo específico individual com as atividades escolares a desenvolver próprias para as suas competências e dificuldades.

\subsection{Sujeito com Autismo Atípico — A}

*-Categoria 'Escola'. A criança frequenta uma escola urbana sediada na Guarda, que integra os ensinos Pré-escolar e $1^{\circ}$ Ciclo do Ensino Básico. É uma escola espaçosa, com áreas funcionais, pois contém espaços complementares comuns, incluindo o exterior.Em termos de organização escolar possui várias salas para atividades, em função das classes etárias, salas de aula, aula de atividades de Enriquecimento Curricular, aula para atividades plásticas e de representação, centro de recursos e biblioteca, sala de atendimento aos pais, etc.

*-Categoria 'Turma'. É uma turma do 3. ${ }^{\circ}$ ano de escolaridade constituída por 20 alunos, com média de idades entreos $7 / 8$ anos. O comportamento e aproveitamento geral da turma são bastante satisfatórios. O aluno A apresenta um comportamento e aproveitamento regulares (dados facultados pela professoratitular e observações).

*-Categoria 'Dados clínicos'. Quando deu entrada no $1^{\circ}$ Ciclo, a criança manifestava comportamentos atípicos, com gestosrepetitivos, que despertavam a atenção da professora titular. Assim, em 2010 foi observada/avaliada naUnidade de Neuro-desenvolvimento e Autismo do Centro Hospitalar de Coimbra, tendo-se diagnosticado PHDA (Autismo Atípico). *-Categoria 'Percurso escolar'. O aluno esteve aos cuidados dos avós até aos 3 anos de idade, momento em que entrou para o jardim-de-infância e, posteriormente deu entrada no $1^{\circ}$ Ciclo com 6 anose no $2^{\circ}$ período ano letivo de 2011/2012, foi transferida para oura escola da 
cidade a pedido da mãe, pois, segundo esta a criança não estava a ser devidamente acompanhada e era rejeitada pelos seus pares.Tendo em conta o Decreto-Lei $n^{\circ} 3 / 2008$, de 7 de janeiro, contempla-se no ProjetoEducativo Individual: o apoio pedagógico personalizado e as adequações no processo de avaliação.

*-Categoria 'História familiar'. Através do processo individual do aluno e da recolha de informação junto dos pais (ficha de anamnese, entrevistas) ficámos a conhecer melhor a família. É uma criança meiga que vive com os pais, sendo a mãe professora e formadora e o pai técnico urbanista. Trata-se duma família com um nível económico médio/alto, tendo ambos pais o grau de licenciatura. São muito recetivos às sugestões da professora titular, professora de Educação Especial, psicóloga e da equipa de pedopsiquiatria que acompanha a criança, mas consideram que o acompanhamento efetuado nesta escola, não é o desejado. $\mathrm{O}$ pai revela um grande descontentamento pela problemática do filho. Na família existem casos de autismo (primo direito) e outros casos não diagnosticados.

*-Categoria 'Caraterização'. Da análise de conteúdo ao Projeto Educativo Individualrecolhemos as seguintes informações: é uma criança meiga, de trato fácil, consegue reconhecer algumas emoções básicas, mas tem dificuldade em exteriorizá-las; não controla a demonstração de afeto; tem dificuldades graves no comportamento social (relação com os outros); manifesta limitações graves nas interações pessoais; procura os adultos em detrimentos dos seus pares, alheando-se em brincadeiras repetitivas; isola-se muitas vezes e revela dificuldades de concentração, atenção e adaptação à mudança. De facto, demonstra comprometimentos na formulação de ideias e no raciocínio abstrato.

Ao nível da comunicação, apresenta dificuldades no raciocínio verbal (tirar conclusões, encontrar absurdos...), na fluência verbal (inventar frases) e muitos comprometimentos no jogo de ideias (meditar, ponderar, especular e refletir). Na memória verbal e numérica e repetitiva, revela dificuldades nassequências simples. A memória verbal e numérica significativa encontra-se bastante afetada, além das dificuldades ao nível percetivo: perceção visual(perceber semelhanças/diferenças, erros em desenhos), perceção auditiva (discriminar e localizarsons), perceção temporal (discriminar dias, meses, anos) e perceção espacial gráfica.Apresenta uma dificuldade moderada na coordenação manual e gráfica: movimentos finos da mão. Demonstra um comportamento dependente nas atividades quotidianas, dificuldade na preparação, organização e realização de tarefas, necessitando de incentivos. Segundo os pais e professores a criança revela obsessões faseadas: medo de doenças, pavor aos germes, lavagem insistentedas mãos, intolerância às luzes coloridas, etc. 
Os pais referiram que os alimentos que ingere têm de ser todos triturados, pois como viu um colega a engasgar-se com uma espinha, nunca mais conseguiu deglutir alimentos sólidos. Revela alguma resistência em alimentar-se, provocando, muitas vezes, o vómito.

\subsection{Sujeito com PHDA - H}

*-Categoria 'Escola'. O aluno frequenta o $3 .^{\circ}$ ano duma escola básica do $1^{\circ}$ Ciclo da cidade da Guarda. Esta instituição funciona desde 1971 tem 3 pisos, um espaço polivalente, salas de aula e de salas de apoio educativo, entre elas a Unidade de Apoio Especializado para a educação de alunos com 'Multideficiência' e'Surdo-cegueira Congénita', sala deatendimento aos pais, biblioteca / centro de recursos, etc.

*-Categoria 'Turma'. O aluno está numa turma mista de $3^{\circ}$ e $4^{\circ}$ ano, constituída por 20 alunos, dois dos quais são repetentes. A média de idades varia entre os 8/ 9 anos.

*-Categoria'Dados clínicos'.O aluno tem 8 anos e segundo o relatório da consulta do Desenvolvimentono Serviço de Pediatria Hospital Distrital da área de residência, apresentando um quadro de PHDA de grau ligeiro a moderado, que não representaqualquer impedimento no seu processo de aprendizagem, nem na sua vida social, necessitando apenas dealgum reforço e apoio acrescido em algumas áreas e, esporadicamente de medicação. Foi observada em 2007, na sequência de uma consulta de rotina com o pediatra, uma vez que a mãe relatava episódios de grande agitação e desconcentração da criança (sono muito agitado). Após o diagnóstico, a criança passou a tomar 'Ritalina' em situações pontuais, quandonecessita duma maior concentração (fichas de avaliação) ou para dormir. Foi observada no Serviço de Psicologia e Orientação da escola revelando grande dependência da mãe, dificuldades de atenção e de autonomia.

*-Categoria 'Percurso escolar'. A criança frequentou o jardim-de-infância duma aldeia dos arredores da cidade da Guarda, ingressando na Escola Básica do $1^{\circ}$ Ciclo aos 6 anos.A professora titular referiu que as queixas sobre o seu mau comportamento e atitudes incorrectas são inúmeras e por parte de toda a comunidade escolar: alunos, professores, assistentes operacionais, pais, etc. Em situação de aula, por exemplo, o aluno bate constantemente com o lápis na mesa, perturba o ambiente normal das aulas, uma vez que distrai os colegas, levando muitos deles a queixarem-se. O seu aproveitamento escolar é pouco satisfatório, pois tem fracos resultados nas disciplinas de Língua e Matemática e, por isso tem aulas de Apoio Pedagógico Acrescido.

Interfaces da Educ., Paranaíba, v.7, n.19, p.23-47, 2016. 
*-Categoria 'História familiar'. A criança é afetuosa, e aparentemente calma, contudo após alguns momentos de interaçãoexpressa um comportamento bastante agitado: mexe em tudo o que vê, não consegue concentrar-senuma dada situação, corre sem parar, ou quando se encontra numa situação ondenão o pode fazer, atira objetos para o chão. Vive com os pais eduas irmãs mais velhas, estando a mãe desempregada. É uma família com um nível económico médio/baixo, pois o pai que é construtor civil tem o $4 .^{\circ}$ ano e a mãe o $9 .^{\circ}$ ano de escolaridade. Pais e uma das irmãs estão presentes na educação do aluno, acatando todas as solicitações e participando em todas as reuniões e consultas. A referida irmã ajuda-o na organização do trabalho escolar. A mãe é bastante nervosa, ansiosa e hipertensa, tomando medicação para o efeito eculpabiliza-se pela problemática do filho, pois, sempre foi mais permissiva com ele do que comas irmãs.

*_Categoria 'Caraterização'. Da análise do processo individual do aluno e da recolha de informação junto dos pais (ficha de anamnese), verificamos que é uma criança meiga e afectuosa com a mãe e em situações de grupo reduzido (mãe e professora), mas com o seu grupo de amigos ou grupo turma, o seu comportamento altera-se revelando agitação e descontrolo de movimentos. É conflituoso, mas tem um grupo de amigos estáveis, que o acompanha em todas as situações. Revela dificuldades de atenção e concentração, sendo pouco persistente na realização das tarefas escolares. Os exercícios que despendem algum tempo para os realizar são postos à margem. Ao nível emocional, o seu comportamento alterna entre momentos de euforia, com momentos pontuais de acalmia. Em situação de conflito tem dificuldade em se expressar, referindo quasesempre que a "culpa" é sempre dele.

\subsection{Sujeito dito "normal" $-\mathbf{N}$}

Este aluno nas categorias 'Escola' e 'Turma'tem as mesmas informações relativas ao do aluno com PHDA, uma vez que frequentam a mesma escola, além de não haver nada a registar na categoria 'Dados clínicos'. Na categoria 'Percurso escolar' a criança frequentou a creche da Santa Casa da Misericórdia desde os 5 meses, tendo posteriormente frequentado o jardim-de-infância. Ingressou na Escola Básica com 5 anos. É empenhada e dedicada nas tarefas escolares e segundo a professora o seu comportamento e aproveitamento são bastante satisfatórios. Na categoria 'História familiar', o seu processo individual e a nossa recolha de informação junto dos pais (ficha de anamnese) possibilitou-nos conhecer a sua família, que tem um nível económico médio/alto, pois a mãe é organizadora de eventos (bacharel) numa 
empresa e o pai é profissional de seguros $\left(12^{\circ}\right.$ ano). Trata-se duma criança simpática e divertida que vive com os pais e uma irmã mais velha. Os pais estão muito presentes na sua educação, sentindo-seorgulhosos do seu desempenho.

$\mathrm{Na}$ categoria ‘caraterização' pudemos confirmar que é um aluno estudioso e empenhado, gosta de desporto, participando em diversas modalidades, faz amizades com facilidade e tenta ajudar os colegas no estudo.Ao nível emocional é muito atenta às manifestações emocionais de quem a rodeia, tentando sempre animar ou consolar das mais variadas maneiras, quem apresente tristeza, ansiedade e descontentamento.

\section{ANÁLISE E INTERPRETAÇÃO DOS RESULTADOS}

Em seguida descrevemos e avaliamos as sessões de trabalho realizadas com o programa e os testes, em cada criança e a respetiva interpretação dos resultadosobtidos.

\subsection{Aplicação da 'Uma caixa cheia de emoções'}

Aplicámos o material "Uma caixa cheia de emoções" numa sala de apoio e pedimos aos alunos em estudo que, através da observação das imagens das 4 emoções básicas, as identificassem. Todos eles identificaram facilmente as imagens 'está triste e feliz', reconhecendo tambémo 'estar zangado', mas utilizaram sinónimos como: chateado, irritado e nervoso. Quanto à situação 'estar com medo', todas utilizaram adjetivos como espantado, admirado e assustado, referindo que conseguiam identificar essas emoções através da boca das crianças apresentadas nas imagens. $\mathrm{O}$ aluno com $\mathrm{M}$ reconheceu as emoções apresentadas, representando-as através da expressão facial. As atividades desenvolvidas com $\mathrm{M}$ foram escassas, pelo facto de não verbalizar.

Passámos à exploração de cada emoção. No caso da imagem 'felicidade', para a criança A, o'ser feliz' é 'ser alegre', para a criança com PHDA é “quando acontece uma coisa boa" e para a criança $\mathrm{N}$ é "ter uma vida com amigos". No caso da imagem "triste", para a criança A significa chorar, para a criança $\mathrm{H}$ é quando acontece algo de mau e para a criança $\mathrm{N}$ é não ser aceite pelos outros. No caso da imagem "zangado", para a criança A é estar-se "enervado"; para a PHDA é ser culpabilizado por algo que não fez e para a N é "ter problemas com os amigos ou com os pais'. No caso da imagem "medo", para a criança A tem 
a ver com o facto de se ver algo terrível; para a criança com PHDA é "ter medo de algumas coisas" e para a criança N (normal) é "quando nos fazem alguma coisa e ficamos com receio".

Enquanto as crianças com Autismo Atípico e PHDAo estar feliz é estar em família, a criança $\mathrm{N}$ fica feliz quando tem bons resultados na escola (preocupação com odesempenho escolar). A criança A está triste quando a professora se zanga com ela; a criança $\mathrm{H}$ quando faz algo de errado e a criança $\mathrm{N}$ quando não tem bons resultados escolares. Por outro lado, a criança H declarou nunca "ter medo"; a criança A tem medo que o pai lhe bata, pois pode partir algum osso (fobia às doenças) e a criança $\mathrm{N}$ tem medo de cair. Relativamente às situações que as deixam "zangadas", para a criança A estas ocorrem quando um menino da escola "anda sempre atrás de mim" (ao ser questionado sobre esta afirmação, o aluno referiu que o tal menino tem um cabelo muito encaracolado e que é igual a uma das imagens apresentadas na caixa, demonstrando dificuldade em aceitar a diferença, nomeadamente neste caso, a raça negra); no caso da criança $\mathrm{H}$, sente-se zangado quando "me mandam asculpas para cima" (considera-se constantemente culpabilizado pelas diversas situaçõesnegativas; a criança $\mathrm{N}$ fica zangada quando não gostam da sua opinião.

Por fim, procedemos à análise dos "cartões-situação" que se inserem em cada emoção. Numa primeira fase, pediu-se às crianças que escolhessem os cartões, ouvissem cada história e respondessem às respetivas questões. Seguidamente fez-se a mesma atividade, mas neste caso, o cartão era imposto e foi o mesmo para cada criança, numa tentativa de fazer um estudo comparativo. Nesta atividade, as respostas não diferiram muito, reconhecendo a razão pela qual as personagens apresentadas se encontravam tristes, alegres, zangadas ou com medo.

Relativamente à escolha dos cartões, pudemos verificar que a criança A nunca quis escolher imagens que representam pessoas doentes, provavelmente pela sua fobia às doenças; para além disso,demonstrou algum constrangimento pelo facto de a professora "ralhar" com ela, pois, como pudemos ela é constantemente chamada à atenção, devido à sua distraçãocontinua; manifestou ainda dificuldade em aceitar as diferenças. A criança $\mathrm{H}$ escolheu sempre cartões com crianças a fazer traquinices e mostrou-se insatisfeito por ser sempre culpabilizado por tudo e por nada. Durante a realização das atividades, este aluno H passou o tempo a manusear todos os cartões. A criança $\mathrm{N}$ selecionou os cartões onde apareciam modalidades desportivas, talvez pelo seu gosto pelo desporto e revelou uma grande preocupação em atingir bons resultados escolares.A utilização deste instrumento e a análise dos dados permite atuar de uma forma mais consciente, no sentido de melhorar a qualidade de vida da criança. 


\subsection{Aplicação da prova projetiva "Era umavez..."}

Todos os alunos criaram as 8 histórias do teste (1 detreino e 7 obrigatórias), com exceção do aluno M, uma vez que, segundo a professora de educação especial e a psicóloga, dadas as suas características, não realizoueste tipo de prova.

A criança A revelou, mais uma vez, aversão às imagens que apresentavam doenças, hospitais ouambulâncias. A aplicação da prova demorou várias horas, sendo necessário fazer diversos intervalos, pois acriança organizou sempre os cartões antes de os escolher; revelou grandes dificuldades em selecioná-los,sendo necessário incentivá-la; alheou-se inúmeras vezes e limitou-se a descrever as imagens. A prova foiaplicada em casa da criança, a pedido da mãe. No cartão II — a doença —, fez diversas perguntas sobreesta temática: "Se eu dobrar muito o dedo posso parti-lo?"; “Doer a barriga é uma doença?”... Nestahistória foi surpreendente a escolha da cena 4 representativa da morte; após um momento de conversa,percebemos que no entender da criança, ficar doente significa morrer. Em quase todas as histórias criadaspor esta criança existem os três elementos realidade, fantasia e aflição, à exceção das histórias I- passeiocom a mãe, IV-pesadelo e VI- briga dos pais, onde surge duas vezes o elemento "fantasia", concluindo-seque as suas vivências estão muito relacionadas com a fantasia.

No caso do aluno H, a aplicação da prova demorou 23 minutos, verificando-se algum empenho e alguma pressa em descobrir o final da história. A prova foi aplicada numa sala de aula,depois das aulas terminarem. Nas histórias I, IV e VII - escola, aparecem todos os referidos elementos. Nahistória II- doença, surge duas vezes "aflição"; nas histórias III- ida à praia, V- dia dos anos e VI, apareceduas vezes "fantasia", concluindo-se que as vivências da criança se relacionam, muitas vezes com afantasia. Na história VI, aparece duas vezes "realidade". Relativamente à criança N, a aplicação da prova demorou 33 minutos, constatando-se atentativa de construção de uma história com uma estrutura lógica. Nas histórias I e III, a escolha dacriança recaiu, duas vezes, sobre cartões de "aflição". Na história V surge duas vezes "fantasia" e nashistórias VI e VII aparece duas vezes "realidade", concluindo-se que esta criança encara muitas situaçõescom recurso à realidade, já que o incumprimento de regras,no âmbito familiar, lhe causa aflição.Todos os sujeitos consideraram a história do "dia dos anos" como sendo a mais feliz; a mais triste,para o sujeito A é a doença e para os sujeitos $\mathrm{H}$ e $\mathrm{N}$ é a briga dos pais.Esta prova permitiu caracterizar emocionalmente os alunos e definir quais as melhoresestratégias para as problemáticas apresentadas, por 
exemplo: exploração do poema "Meninos detodas as cores", de Luísa Ducla Soares, para trabalhar a diferença; representação de situações de doençae tratamento; leitura da obra "As meninas, a vovó... e as saudades de quem foi para o céu”, de CeciBaptista Mariani, para abordar a morte, entre outras.

\section{Propostas de estratégias de intervençãofuturas}

Este estudo (exploratório) permitiu-nos compreender preponderância as emoções no processo educativo, como meio de formação e autorregulação do indivíduo.A aplicação do teste projetivo e a utilização do material didático proporcionou um conhecimento mais aprofundado da dimensão emocional no autismo atípico, na microcefalia e PHDA, levandonos a propor estratégias de intervenção ou atuaçõespara os professores e/ou escola inclusiva. Os resultados obtidos, na base da teoria fundamentada, permitiram-nos compreender que, nos casos de microcefalia, as estratégias mais adequadas são: utilizar material manipulável e visualmenteatrativo, fornecendo informação verbal; demonstrar é melhor que explicar oralmente; apresentar as instruções, uma de cada vez; elogiar é fundamental e encorajar a autonomia, tanto quanto possível. (ANTUNES, 2012).

No caso do aluno com autismo deve-se: falar calmamente; usar instruções curtas; ajustar a fraseologia e evitar o uso de inferências e expressões ambíguas; esclarecer o significado das palavras; usar gestos e orientação física; aliar o suporte visual às instruções verbais e fornecer quantidades mínimas de materiais de trabalho e equipamentos (CUXART, 2000; HEWITT, 2006; RIVIÉRE, 2001). Relativamente às crianças com PHDA as estratégiasadequadas são: minorar fatores de distração; facilitar a atenção com material visualmente atrativo e manuseável; sublinhar os aspetos mais relevantes; apresentar instruções curtas e dada uma de cada vez, acompanhadas do contacto visual e elogiar é fundamental (ANTUNES, 2012).

Sugerimos o seguinte material didático para trabalhar as emoções:

*-Jogo "As Expressões" que consiste na identificação de emoções e da sua associação, com 10 expressões faciais diferentes e 4 personagens reais. O objetivo é promover as competências sociais e discursivas, o reconhecimento das emoções, de modo a desenvolver a capacidade de observação, expressão oral e escrita. 
*_“Caixa Cheia de Emoções” é um jogo que ajuda as crianças a aproximarem-se do que se passa dentro delas. Sendo um material testado em crianças de 4 e 5 anos, pode usar-se em outras situações para que as crianças falem e brinquem sobre emoções.

*_“Ação Provoca Emoção” é um conjunto de histórias que estimula a reflexão sobre as nossas emoções e dos outros, permitindo desenvolver o vocabulário necessário para expressar as emoções. Em cada história as expressões faciais dos personagens aparecem em detalhe. O objetivo é identificar as emoções e suas 'nuances', a promoção social, a competência discursiva, o raciocínio lógico, a extensão do vocabulário.

*-Jogo das "Relações e Emoções" tem como objetivos: desenvolver as competências sociais e emocionais; expressar sentimentos; reconhecer sequências; desenvolver a linguagem e a escuta ativa; desenvolver competências criativas e vocabulário; incentivar a narrativa oral e a reprodução para a escrita.

*-O Medo está na nossa Cabeça" apresenta situações reais para serem interpretadas. Os objetivos assentam no reconhecimento sequencial dos acontecimentos cronológicos, o raciocínio lógico, consciencialização dos medos e saber expressá-los e ultrapassá-los.

*-A "Coragem, Enfrenta os Medos" é composto por várias histórias onde, cada história se inicia com uma situação básica em que o 'João' está assustado. As crianças enfrentam as suas próprias fantasias num ambiente seguro, falando sobre elas.

*-Bingo de Sons - Emoções - consiste na associação das emoções básicas, promovendo as competências sociais e discursivas, identificação das diferentes emoções para desenvolver a capacidade de observação e superação de conflitos.

*-Jogo Como Posso Emendar? ajuda a refletir sobre a 'culpa' e a inocência, descrevendo conflitos morais, classificaas emoções, permite o reconhecimento dos erros e responsabilidades, fomenta o raciocínio lógico, melhora as expressões.

Enfim, quando a pessoa demonstra capacidade para lidar com as emoções, se motiva a si mesmo, controla os impulsos ou é capaz de canalizar as emoções para situações apropriadas, evidencia habilidades emocionais. (STRONGMAN, 2004).

\section{REFERÊNCIAS}

ANTUNES, A. L. Mal-entendidos. Da hiperactividade à síndrome de Asperger, da dislexia às perturbações do sono: as respostas que procura. Lisboa: Verso de Kapa, 2012.

ARÀNDIGA, A.V. La inteligencia emocional de los hijos. Cómo desarrollarla? Madrid: EOS, 2006. 
ASENSIO, J. Cómo prevenir el fracaso escolar. Barcelona: CEAC, 2006.

BISQUERRA, A.R. Provas temáticas na clínica infantil. Madrid: Síntesis., 2009.

Cómo educar las emociones?La inteligencia emocional en la infancia y la adolescencia. Espulgues de Llobregat: Hospital Sant Joan de Déu, 2012.

BISQUERRA, A.R.; PÉREZ, N. 'Las competencias emocionales'. Educación, XXI, Vol. 10, p. 61-82, 2007.

BOGDAN, R.; BIKLEN, S. Investigação qualitativa em educação: uma introdução à teoria e aos métodos. Porto: Porto Editora, 1994.

CARPENA, A. Educación socioemocional en la etapa de primaria.Vic/Barcelona: EUMO, 2003.

CUXART, F. Autismo infantil y otros trastornos del desarrollo. Sevilla: Aljibe, 2000.

DAMÁSIO, A. O Erro de Descartes: emoção, razão e cérebro humano. Mem Martins: Publicações Europa-América, 1994.

O Sentimento de si: o corpo, a emoção e a neurobiologia da consciência. Mem

Martins: Publicações Europa-América, 1999.

O Mistério da consciência: do corpo e das emoções do conhecimento de si. São

Paulo, SP: Companhia das Letras, 2000.

DAMÁSIO, A. Ao encontro de Espinosa: as emoções sociais e a neurologia do sentir. Lisboa: Temas e Debates, 2012.

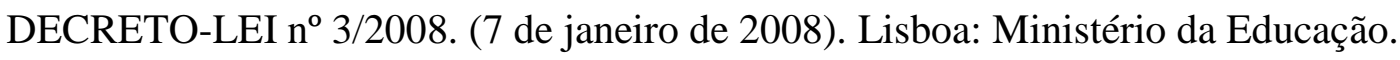

DEPONDT, L; KOG, M.\&. MOONS, J. Uma caixa cheia de emoções: manual e material. Lisboa: Estúdio Didáctico, 2004.

ESTRADA, R. “Era uma vez...”: emoções, defesas e fantasias. Porto: Universidade Fernando Pessoa, 2008.

FAGULHA, T. A Prova “Era uma vez...": manual e material. 2. ed. Lisboa: CEGOC/TEA, 2003.

“Era uma vez...": prova projectiva para crianças. Manual e material.

Lisboa:CEGOC/TEA, 2010.

GARDNER, H. Inteligências Múltiplas: a teoria na prática. São Paulo, SP: Artmed Editora, 2000.

GOLEMAN, D. Inteligência emocional. Lisboa: Círculo de Leitores, 1996. 
GROP. Actividades para el desarrollo de la inteligencia emocional en los niños. Barcelona: Parramón, 2009.

GUERRA, I.S. Pesquisa qualitativa e análise de conteúdo: sentidos e formas de uso. Cascais: Princípio Editora, 2008.

HENNESSEY, B. A. Promoting social competence in school-aged children: The effects of the open circle/Program. Journal of School Psychology, 45, p. 349-360, 2007.

HEWITT, S. Compreender o autismo: estratégias para alunos com autismo nas escolas regulares. Porto: Porto Editora, 2006

MORENO, A.; PALENCIA, L. Sentir y Pensar: programa de inteligencia emocional para niños y niñas de 6 a 8 años. Madrid: SM, 2001.

NEWEN, A.; ZINK, A. O jogo das emoções. Mentes \& Cérebro. n. ${ }^{\circ}$ 195, p.38-45, (abril), 2009. Disponível em: <http://www.claudetedemorais.com.br/emocoes2.html>. Acesso em: 2 maio 2013.

PICARD, R.; COSIER, G. Affective intelligence - the missing link? Bulletin Technology Journal, v.15, n. 4, p. 151-152, 1997.

RIVIÈRE, A. Autismo. Madrid: Ed. Trotta, 2001.

SALMURRI, F. Libertad emocional: estrategias para educar las emociones. Barcelona, Paidós, 2004

SALOVEY, P.; MAYER, J.D. Emotional intelligence. Imagination, Cognition and Personality, n. ${ }^{\circ}$ 9, p. 185- 211, 1990.

SHORE, A. N. Affect regulation and the origin of the self: the neurobiology of emotional development. Hillsdale/N.Jersey: Earlbaum, 1994.

SLUYTER, D.; SALOVEY, P. Inteligência emocional da criança: aplicações na educação e no dia-a-dia. Rio de Janeiro, RJ: Editora Campus, 1999.

SMITH, C.; STRICK, L. Dificuldades de Aprendizagem de A a Z: um guia completo para pais e educadores. Porto Alegre, RS: Artmed Editora, 2001.

STRONGMAN, K.T. A psicologia da emoção. Lisboa: Climepsi, 2004.

VALLÉS, A.; VALLÉS, C. Inteligencia emocional: aplicaciones educativas. Madrid: Editorial EOS, 2000.

WALLON, H. A evolução psicológica da criança. Lisboa: Edições 70, 1968. Do acto ao pensamento. Lisboa: Moraes Ed., 1978. 
O marca-passodas emoções no ritmo de criançasportuguesas com necessidades educativas ...

YIN, R. K. Pesquisa estudo de caso: desenho e métodos. 2. ed. Porto Alegre, RS: Bookman, 1994. 